\title{
Game-Theoretical, Strategic forward Contracting in the Electricity Market
}

Pär Holmberg 


\title{
Game-theoretical, strategic forward contracting in the electricity market
}

\author{
Pär Holmberg*
}

May 28, 2008

\begin{abstract}
Forward sales is a credible commitment to aggressive spot market bidding, and it mitigates producers' market power in electricity markets. Still it can be profitable for a producer to make such a commitment if it results in a soft response from competitors in the spot market (strategies are substitutes). The optimal contracting level of a risk-neutral producer is determined by the extent to which strategies are substitutes and the slope of the residual demand in the forward market. Conditions under which strategies are substitutes are identified for a two-stage game with supply function competition and capacity constrained producers.
\end{abstract}

Keywords: supply function equilibrium, forward market, strategic contracting, arbitrage, strategic substitutes, oligopoly, electricity market

JEL codes: C72, D43, D44, G13, L13, L94

\footnotetext{
* Research Institute of Industrial Economics, Stockholm, and Department of Economics, Uppsala University. Box 55665, SE-102 15 Stockholm, Sweden, phone +46 1847176 35, fax + 468665 4599. E-mail:

Par.Holmberg@ifn.se. I appreciate comments by seminar participants at Uppsala University (March 2007), Cambridge University (May 2007), Oxford University (June 2007), 22 ${ }^{\text {nd }}$ European Coference on Operational Research in Prague (July, 2007), and Guelph University (February 2008). The work has been financially supported by the Jan Wallander scholarship of Svenska Handelsbanken and the Swedish Energy Agency.
} 


\section{INTRODUCTION}

It has been shown both empirically (Wolak, 2000) and theoretically (von der Fehr and Harbord, 1992; Newbery,1998b; Green, 1999) that forward contracts significantly mitigate market power in electricity markets. Thus from a welfare perspective it is beneficial that generators in the world's restructured electricity markets tend to cover a large part of their sales in the contract market (Green, 1999; Bushnell, 2007). However, it seems that this is to a large extent driven by regulatory intervention, at least in many U.S. markets (Bushnell, 2007). Moreover, regulated contracting is only a transitory arrangement, which will expire over the next several years (Bushnell, 2007). Thus predicting the contracting level when such decisions are left to the market becomes an increasingly important question. This paper addresses this issue by means of a two-stage game in which producers compete with supply function strategies as in the electricity market.

Apart from regulatory requirements, what are the incentives behind generators' forward sales? It is evident that hedging and arbitrage opportunities play an important role. These mechanisms are well-studied for markets with perfect competition. But the problem with electricity markets is that competition is often imperfect and in this case forward contracting is also driven by strategic interaction with competitors and potential entrants. Newbery (1998b) shows that generators may use contract sales to keep output high and spot prices low to deter entry. This can be classified as a 'top dog' strategy in the taxonomy of business strategies outlined by Fudenberg and Tirole (1984), and Bulow et al. (1985). Because, as illustrated in Fig. 1, selling forward makes a profit-maximising generator less interested in mark-ups in the spot market and it is accordingly a credible commitment to aggressive spot market bidding; selling forward contracts makes a producer 'look tough'.
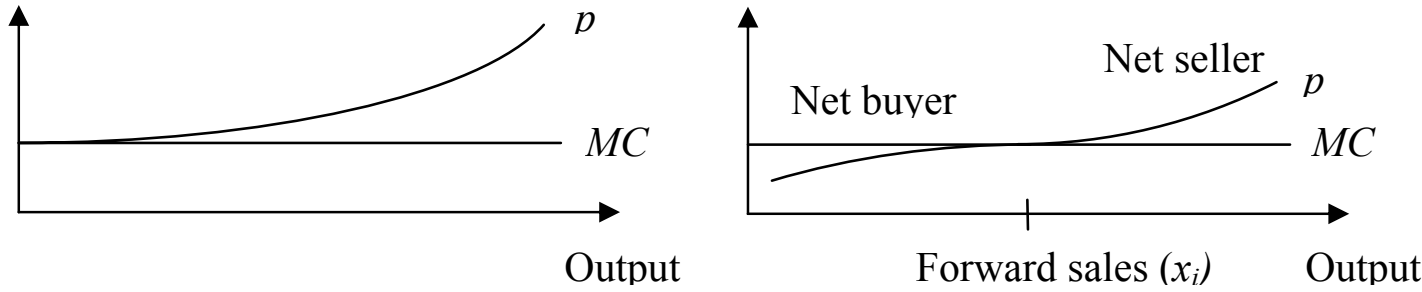

Figure 1. With forward contracts, a producer becomes less interested in spot market markups. 
Strategies of incumbents are substitutes if a commitment to aggressive spot market bidding is met with a soft response in the spot market, i.e. competitors shift their output inwards. In this case firms have incentives to use the 'top dog' strategy also against incumbent competitors, as illustrated in the two-stage Cournot model by Allaz and Vila (1993). This gives rise to a prisoners' dilemma: given competitors' forward positions, each incumbent producer has incentives to sell forward and when they all do so, all firms end up worse off (Mahenc and Salanié, 2004). As a result competition is tougher on the spot market and welfare is improved compared to a situation without forward trading. This strategic effect has also been verified experimentally by Brandts et al. (2006). However, Mahenc and Salanié (2004) show that the result can be reversed in a market with competition in prices, which are strategic complements. In this case, firms buy their own production in the forward market (negative contracting) in order to soften competition in the spot market, which corresponds to the 'puppy dog' strategy in Fudenberg and Tirole (1984). Thus forward trading reduce welfare in the model by Mahenc and Salanié (2004). Elastic forward supply - as in the models by Newbery (1998b), Green (1999), and Chung et al. (2004) - introduces an additional mechanism beyond the models by Allaz and Vila (1993) and Mahenc and Salanié (2004), which can be referred to as the indirect strategic effect. When one firm increases its forward sales this will change competitors' forward sales (via the forward price), which in its turn influences how aggressive competitors bid in the spot market.

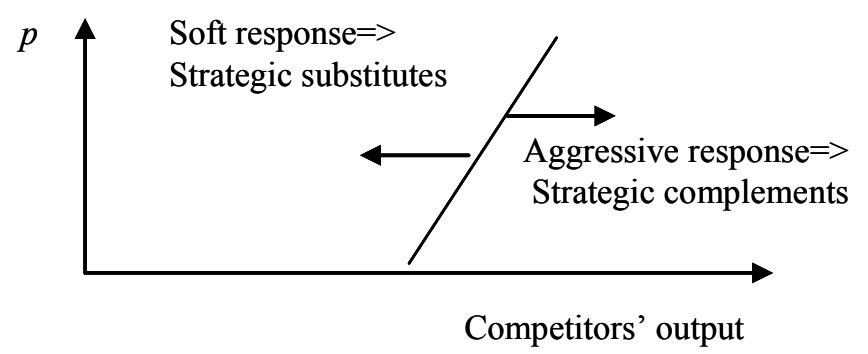

Figure 2. Competitors' response to increased forward sales can be either soft as in the Cournot model by Allaz and Vila (1993) or aggressive as in the Bertrand model by Mahenc and Salanié (2004).

Since forward contracting incentives are diametrically different under price and quantity competition, one needs to consider the competition process in detail when analysing strategic contracting in the electricity market. Most electricity spot markets are organised such that producers submit offer curves to a uniform-price auction. This is done before demand has 
been realised, i.e. demand is uncertain. In addition, electricity production costs are fairly wellknown (approximately common knowledge). Bolle (1992), and Green and Newbery (1992), observed that these characteristics of the market agrees very well with the market assumptions behind the supply function equilibrium under uncertain demand, which was introduced by Klemperer and Meyer (1989). A potential problem with this model is that there are multiple equilibria if the demand variation is not sufficiently large.

Previous studies of two-stage supply function competition are limited to producers with constant (Newbery, 1998b) and linear marginal costs (Green, 1999; Chung et al., 2004). Moreover, spot market equilibria in these models have been selected such that strategies are direct neutrals, i.e. a firm does not adjust its output curve after observing a change in a competitor's forward sales. This paper shows that strategies are direct substitutes if marginal costs are convex, the residual demand of each firm is concave and demand variation is sufficiently large, so that a unique equilibrium can be determined in the spot market. I derive a general forward contracting condition for a market with supply function competition, asymmetric firms and general cost functions. It is shown that the optimal contracting level of a risk-neutral firm is determined by two factors, which can be categorized as a quantity effect and a price effect. Increased forward sales results in a decreased forward price - the price effect - which is bad for revenues and profits. The quantity effect is given by the extent to which strategies are substitutes: a producer can increase its output at competitors' expense if strategies are substitutes, so that they shift their output curves inwards when the producer increases its forward sales. It is proven that in the subgame perfect Nash equilibrium a marginal change in the spot price does not influence the expected profit. This is envelope result follows from that bids in the spot market are sequentially rational. The general condition is evaluated for specific market conditions: perfectly elastic forward supply, perfectly inelastic forward supply and perfectly elastic forward demand. The latter is a plausible assumption for a market with many risk-neutral speculators. In this particular case, mark-ups will be small if strategies are direct substitutes and demand uncertainty is small.

The structure of the paper is as follows. Background on the electricity market is given in Section 2. Notation and assumptions are introduced in Section 3. Forward contracting and supply function strategies are analysed in Section 4. Section 5 concludes.

\section{THE ELECTRICITY MARKET}

Electricity is produced by many different technologies that often have different marginal costs. The plants of a producer are used in merit order, starting with the ones that have the 
lowest marginal cost, such as nuclear power or hydro-power. Last in the merit-order are typically peaking power plants, such as gas turbines that burn natural gas. They are characterized by high marginal costs and low investment costs, which is a comparative advantage for plants used only under peak demand. Due to the merit-order, marginal costs of a producer increase with output. There are some local deviations from this trend, due to startup costs of a plants, which introduce local non-convexities in the production costs, but they are normally neglected in analyses of electricity markets. Even if electricity is produced by various technologies it is still a very homogeneous good suitable for trade at commodity exchanges and auctions. Typically there are few producers and many consumers in the market. In addition, demand is to a large extent determined exogenously, e.g. by the weather, and it is very inelastic, especially in real-time. Thus the market power that can be exercised by consumers is small compared to the market power of power producers, which can be significant.

Due to ramp-rates in many production technologies, production plans are scheduled the day before delivery, and the day-ahead market is an important component in this planning process. This wholesale market, which normally is more liquid than the real-time market, provides strike prices for most financial contracts. It is organized as a double auction to which consumers and producers submit bid curves and offer curves, respectively. The market clearing price is determined by the intersection of the bids and offers. As in a uniform-price auction, all accepted bids pay the market clearing price and all accepted offers are paid this price. ${ }^{1}$ There is normally a separate price and auction for each delivery period, which is typically $0.5 \mathrm{~h}$ or $1 \mathrm{~h}$ long.

Electricity is special in that it is very expensive to store, so production must equal consumption at every moment. The system operator uses a real-time or balancing market to make necessary adjustments in production (and consumption to the extent that it is elastic) during the delivery period by accepting additional power production from producers or by selling back electricity to producers. Offer curves to the balancing market are submitted before the delivery period starts and are valid during the whole delivery period. Thus the system operator's demand is uncertain when offers are submitted. System imbalances arise because of unexpected changes in wind and temperature, unexpected production outages or unexpected transmission-line failures. In very extreme cases, multiple unexpected events can lead to that the scheduled reserve capacity - expected available production capacity subtracted

\footnotetext{
${ }^{1}$ Most spot and real-time markets are organized as uniform-price auctions, but the real-time market in Britain, which is organized as a pay-as-bid auction, is an exception.
} 
by expected demand - is not enough to meet the system imbalance. In this case, demand has to be rationed to avoid a system collapse, and the price is set equal to the price cap. One motivation for the use of price caps is that consumers who do not switch off their equipment when the electricity price becomes very high do not necessarily have a high marginal benefit of power. It may be that the residential consumer is not at home or that he/she is not aware of the high price. Moreover, residential consumers may not face the real-time price, because of long-term contracts. Due to these imperfections, it will be welfare maximizing to ration demand at some very high reservation price, which often is set to an estimate of the value of lost load (VOLL) (Stoft, 2002).

The loss-of-load probability (LOLP) is typically very small, but always positive. No matter how large the reserve margin is, sufficiently many simultaneous unexpected events that decrease the production or reserve capacity, or increase the demand will lead to a power shortage. LOLP during a particular delivery period can be estimated from the scheduled reserve margin, the probability distribution of demand and from the probabilities of having production failures in individual plants. Newbery (1998a) shows that the LOLP estimated by the system operator in Britain decreases exponentially with the scheduled reserve margin. Using data provided in Newbery's paper and adjusting for that the system operator consistently overestimated LOLP, I roughly estimate LOLP during an half-hour to $0.1 \%$ when the scheduled reserve margin is $10 \%$ and that it roughly decreases by a factor 100 for every additional $10 \%$ of reserve capacity. ${ }^{2}$ However, these estimates are indeed very uncertain, and are only intended to give some feeling of the magnitude of LOLP and how it depends on the reserve capacity.

Electricity prices are volatile, partly because electricity is not suitable for large-scale storage. To hedge their risks, market participants can buy and sell various derivative contracts, e.g. futures and forward contracts. These contracts commit the parties to buy and sell the contracted quantity at the spot market at the agreed delivery price. In most cases the contracts are financial, so no physical transaction takes place. Forward contracts are normally traded over the counter, and futures contracts at power exchanges. Another difference is that the account of holders of forward contracts is adjusted each day to reflect losses/gains due to changes in the forward price. This procedure is called marking to market. Even if there are differences between forward and forward contracts, they are in most circumstances

\footnotetext{
${ }^{2}$ The values are estimated from Fig. 5 in Newbery (1998a) and that capacity payments in the old pool were proportional to LOLP. It is assumed that the system operator have overestimated the LOLP by a factor 50. This very uncertain factor is based on the reasoning in the appendix of Newbery (1998a).
} 
sufficiently small to be ignored in a theoretical analysis (Hull, 1997), and in this paper I use the term forward contract for both types of contracts. The day-ahead market is different to other forward markets: it is an auction (as mentioned earlier), contracts are physical and the strike price is given by the real-time price.

It is reasonable to assume that the correlation between electricity prices and the stock market as a whole is weak, i.e. the risk in the electricity market is mainly non-systematic. Ideally non-systematic risks can be completely eliminated by holding a well-diversified portfolio (Hull, 1997). One would therefore expect that the risk premium for risks carried in the electricity market would be small. However, many empirical studies suggest that risk premia can be large in electricity markets as in Longstaff's and Wang's (2004) study of the PJM market (U.S.). Kristiansen (2007) have a similar conclusion for Nordpool (Nordic countries). It is possible that the large risk premia arise because the electricity market is immature, at least the Nordpool market shows such signs (Kristiansen, 2007).

Financial trading is anonymous in most power markets, and a firm's forward and futures positions are not revealed to competitors. But a producer can anyway get a rough estimate of changes in competitors' total futures positions by analysing changes in the turn-over in the forward market and the forward price, see the model by Ferreira (2006), for example.

\section{MODEL}

Producers' game-theoretical trading strategies in the electricity market are modelled by a twostage game. The first stage represents the forward market. As in the day-ahead market forward contracts are traded in an auction and contracts are physical (assuming financial contracts would not change the results of the analysis). The second stage represents the realtime market; a uniform-price auction to which firms submit supply function bids. It is assumed that bids in the real-time market are sequentially rational. Thus we calculate the subgame perfect Nash equilibrium of the two-stage game.

There are several electricity producers indexed by $i=1, \ldots N$. Firms' forward sales are denoted by $\mathbf{x}=\left(x_{i}\right)_{i=1, \ldots, N}$. Let $x=\sum_{i=1}^{N} x_{i}$ and $x_{-i}=\sum_{j \neq i} x_{j}$. Forward supply is assumed to be smooth in the forward price, $p^{f}$. Firm $i$ 's output in stage 2 is denoted by $q_{i}$. Forward supply and output are both assumed to be non-decreasing in the forward price and real-time price, $p$, respectively. ${ }^{3}$ Firm $i$ 's net supply (output net of forward contracts) is denoted by $s_{i}(p)=q_{i}(p)$ -

\footnotetext{
${ }^{3}$ Non-decreasing offer-curves are required by most day-ahead and real-time markets.
} 
$x_{i}$. Let $q(p)=\sum_{i=1}^{N} q_{i}(p), q_{-i}(p)=\sum_{j \neq 1} q_{j}(p), s_{-i}(p)=\sum_{j \neq i} s_{j}(p)$, and $s(p)=\sum_{i=1}^{N} s_{i}(p)$. In the comparative statics analysis of the equilibrium in the real-time market, the superscript 0 is used to denote the equilibrium before, and 1 is used to denote the equilibrium after the change in forward sales. Let $t_{j}(p)$ be the change in the supply function of firm $j$ after changed forward sales, i.e. $t_{j}(p) \equiv s_{j}{ }^{1}(p)-s_{j}{ }^{0}(p)$. The cost function of firm $i, C_{i}\left(q_{i}\right)$, is common knowledge. It is increasing, convex and twice continuously differentiable up to the capacity constraint, $k_{i}$.

Electricity demand is subject to an exogenous shock, $\varepsilon$, which is a random variable with continuously differentiable, strictly positive probability density everywhere on the support $[\underline{\varepsilon}, \bar{\varepsilon}]$. Conditional on the information available to consumers and producers in stage 1 , the shock density and probability distribution is denoted by $f(\varepsilon)$ and $F(\varepsilon)$, respectively. $D(p, \varepsilon)$ is consumers' demand curve in the delivery period (stage 2). It is assumed that individual consumers have no market power and that risk-neutral arbitrageurs eliminate arbitrage opportunities. Thus in equilibrium the forward price equals the expected spot price. The forward demand of consumers and speculators is assumed to be smooth and nonincreasing in the forward price.

In the first stage of the game speculators and consumers submit their offer and bid curves simultaneously to the forward market. Accordingly, strategies in the forward market cannot be made contingent on competitors' chosen strategy. Thus if one or several agents deviate from their equilibrium strategy, the resulting forward price may differ form the expected spot price, as in the model by Ferreira (2006). This set-up differs from models by e.g. Allaz and Vila (1993), Newbery (1998b), Green (1999) and Chung et al. (2004), where the forward price equals the expected spot price also out of the equilibrium path. I find that their assumption is difficult to motivate game-theoretically and it is unnecessarily restrictive, because it does not simplify the analysis. It is assumed that agents have symmetric information in the forward market. This implies that the residual forward demand of each agent is known in equilibrium and accordingly slopes of forward supply and forward demand of the agents cannot be endogeneously determined. Instead they are exogeneously given as in Newbery (1998b), Green (1999) and Chung et al. (2004).

Each producer is risk-neutral and acts in order to maximize its expected profit, $\mathrm{E}\left[\pi_{i}(\varepsilon, \mathbf{x})\right]$. When producer $i$ changes its forward sales, competitors' output curves in the spot 
market change via two mechanisms. Let $W_{i}^{D}(p, \mathbf{x})=\frac{\partial q_{-i}(p, \mathbf{x})}{\partial x_{i}}$ denote the direct effect, i.e. competitors adjust their output curve after observing/inferring the forward sales of firm $i$. We say that strategies are direct substitutes when $W_{i}^{D}(p, \mathbf{x})<0$. There is also an indirect effect, $W_{i}^{I}(p, \mathbf{x})=\sum_{j \neq i} \frac{\partial q_{-i}(p, \mathbf{x})}{\partial x_{j}} \frac{\partial x_{j}}{\partial p^{f}} \frac{d p^{f}}{d x_{i}}$. When firm $i$ increases its forward sales the forward price changes, which automatically adjust competitors' forward sales. In its turn this adjustment will shift competitors' output curve. We say that strategies are indirect substitutes when $W_{i}^{I}(p, \mathbf{x})<0$. Let $W_{i}$ be the sum of the direct and indirect effect. Strategies are substitutes when $W_{i}(p, \mathbf{x})<0$.

The analysis of the direct strategic effect for the capacity-constrained SFE is limited to a duopoly market. This part of the analysis is more restrictive in other aspects as well. The support of the shock distribution is assumed to be sufficiently wide, so that a SFE can be uniquely determined from the capacity constraints. In order not to rule out the existence of a SFE, firms are assumed to have the same marginal cost at the contracting point, i.e.

$C_{1}^{\prime}\left(x_{1}\right)=C_{2}^{\prime}\left(x_{2}\right)=p_{0} \cdot{ }^{4}$ Moreover, $C_{i}^{\prime \prime}\left(x_{i}\right)=0$, so that all firms have the same marginal cost at the contracting point also after marginal changes in the forward sales.

\section{ANALYSIS}

The subgame perfect Nash equilibrium of the two-stage game can be solved using backward induction. Sequentially rational real-time market bids are analysed in Section 4.1. Section 4.2 analyzes the strategic effects for capacity-constrained SFE. Given the sequentially rational real-time market bids, conditions for optimal contracting can be derived in Section 4.3. Section 4.4 evaluates the contracting condition for specific market conditions - perfectly elastic forward supply, perfectly inelastic forward supply, and perfectly elastic demand.

\subsection{The real-time market}

In the last stage of the game, producers observe/infer competitors' forward contracts and then submit supply function bids to the electricity auction. In the Nash equilibrium of the real-time

\footnotetext{
${ }^{4}$ Anderson and $\mathrm{Hu}$ (2008) show that the existence of SFE can normally be ruled out for markets in which $C_{i}^{\prime}\left(x_{i}\right) \neq C_{j}^{\prime}\left(x_{j}\right)$ if boundary conditions are imposed both at maximum capacity and zero capacity.
} 
market, an arbitrary firm $i$ will, given competitors' real-time market bids, $s_{-i}(p)$, choose its supply function such that its profit is maximized for each shock outcome. Thus, as in Anderson and $\mathrm{Xu}$ (2005), sequentially rational real-time market bids (net of forward contracts) satisfy the first-order condition derived by Klemperer and Meyer (1989) for all levels of forward contracting. ${ }^{5}$

$$
s_{i}+\left[\frac{\partial D}{\partial p}-\frac{\partial s_{-i}}{\partial p}\right]\left[p-C_{i}^{\prime}\left(q_{i}\right)\right]=0
$$

Note that forward contracting influences the marginal costs, which are determined by total output rather than net-sales in the spot market. Corresponding conditions are derived by Newbery (1998b), Green (1999), and Chung et al. (2004) for cases with constant and linear marginal costs. The equation can be rewritten in the following form.

$$
\frac{p-C_{i}^{\prime}\left(q_{i}\right)}{p}=\frac{-s_{i} / p}{\frac{\partial D}{\partial p}-\frac{\partial s_{-i}}{\partial p}}
$$

An intuitive interpretation of the KM condition is that, each producer acts as a monopolist with respect to its residual demand for each shock outcome and the optimal price of a producer is given by the inverse elasticity rule (Tirole, 2003) for each shock outcome. As the profit is maximized for each shock outcome, this implies that the optimal supply curves do not depend on risk aversion or on the probability distribution of the shock outcomes. Note that the condition in (1) is also valid when firm $i$ is a monopolist and when firms engage in Cournot competition in the real-time market; in both cases $\frac{\partial s_{-i}}{\partial p}=0$.

\subsection{The strategic effect for capacity constrained SFE}

The strategic effects are determined by the sensitivity of the SFE in the real-time market to marginal changes in the forward sales. A comparative statics analysis is complicated by the fact that there is a continuum of solutions to the first-order condition in (1) (see Fig. 3), and a boundary condition or integration constant is required to single out one equilibrium. In previous work on strategic forward contracting for a market with supply function competition, the boundary conditions were chosen such that competitors supply functions do not change when a firm increases its forward sales (Newbery, 1998b; Green, 1999; Chung et al., 2004).

\footnotetext{
${ }^{5}$ Note that the notation used in this paper is different to the one in Anderson and Xu (2005). In their paper output is denoted by $S_{i}(p)$ and forward sales are denoted by $Q_{i}$.
} 
Thus strategies are direct neutrals. Theoretically, it would also be conceivable that producers coordinate to more competitive bidding when one firm increases its forward sales. This would imply that $W_{i}^{D}(p, \mathbf{x})>0$, i.e. strategies are direct complements. On the other hand, if producers would coordinate to less competitive bidding when one firm increases its forward sales, then strategies would be direct substitutes, $W_{i}^{D}(p, \mathbf{x})<0$.

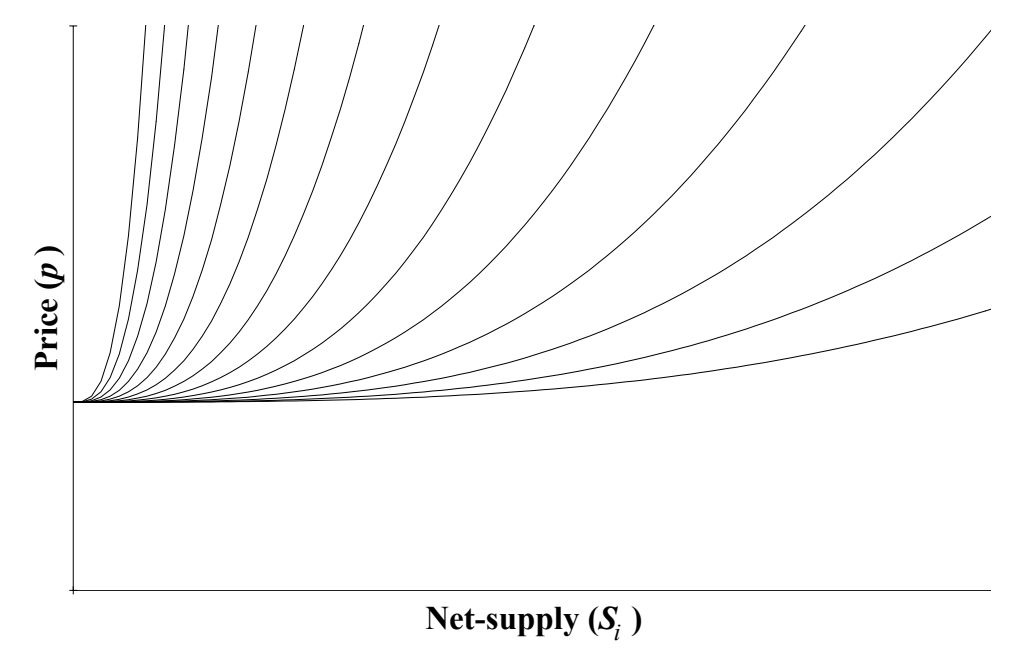

Figure 3. Without a boundary condition there is a continuum of solutions to the first-order condition.

As strategic forward contracting very much depends on the parameter $W_{i}^{D}(p, \mathbf{x})$, we would like to pin down this parameter more accurately, and I will argue that we can do that by considering the influence from capacity constraints. To simplify the reasoning, I will restrict attention to the interval $\left(p_{0}, \bar{p}\right)$. But it is straightforward to derive analogous results for the interval $\left(p, p_{0}\right)$. Previous work has shown that capacity constraints can significantly reduce the range of possible equilibrium solutions (Green and Newbery, 1992; Baldick and Hogan, 2001; Genc and Reynolds, 2004;; Anderson and Hu, 2007). In particular, a unique equilibrium will be singled out if maximum demand is high enough to make the capacity constraints of all (but possibly one) firms bind with a positive probability, which could be arbitrarily small (Holmberg, 2007; Holmberg, 2008). With sufficiently inelastic demand in the duopoly market, no capacity constraints bind below the price cap and Klemperer and Meyer's (1989) first-order condition is satisfied for both firms in the interval $p \in\left(p_{0}, \bar{p}\right)$. Thus 


$$
\left\{\begin{array}{l}
s_{1}+\left[\frac{\partial D}{\partial p}-\frac{\partial s_{2}}{\partial p}\right]\left[p-C_{1}^{\prime}\left(s_{1}+x_{1}\right)\right]=0 \\
s_{2}+\left[\frac{\partial D}{\partial p}-\frac{\partial s_{1}}{\partial p}\right]\left[p-C_{2}^{\prime}\left(s_{2}+x_{2}\right)\right]=0 .
\end{array} \quad \forall p \in\left(p_{0}, \bar{p}\right) .\right.
$$

The capacity of one firm, typically the smaller firm, starts to bind exactly when the real-time price reaches the price cap. Without loss of generality I refer to it as firm 2 . The other firm, which I refer to as firm 1, offers its remaining capacity along the price cap (Holmberg, 2005; Holmberg, 2007). The length of this segment can be uniquely chosen such that a nondecreasing solution results (Holmberg, 2005; Holmberg, 2007). Thus the end-conditions of the system of first-order equations are:

$$
\left\{\begin{array}{c}
s_{1}(\bar{p}-) \leq k_{1}-x_{1} \\
s_{2}(\bar{p})=k_{2}-x_{2}
\end{array}\right.
$$

Moreover, we realize from the system of first-order equations in (2) that the solution must satisfy

$$
s_{1}\left(p_{0}\right)=s_{2}\left(p_{0}\right)=0 .
$$

The duopoly equilibrium is illustrated in Fig. 4.

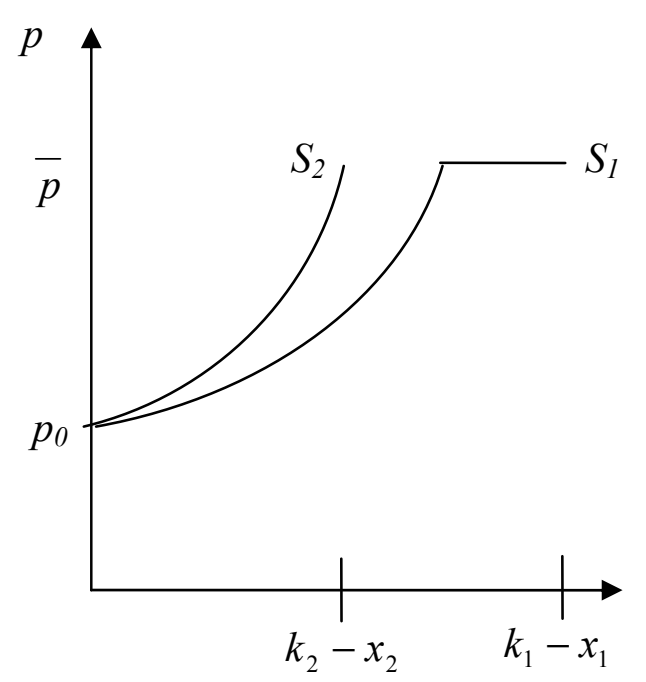

Figure 4. The capacity constrained SFE in a duopoly market.

The following definitions are useful when performing comparative statics of capacityconstrained supply function equilibria. 
Definition 1. The notion capacity-constrained supply function equilibrium is used to denote an equilibrium that is given by non-decreasing solutions of the system of first-order conditions in (2) and that satisfy the boundary conditions in (3) and (4).

Definition 2. The notion stable capacity-constrained SFE is used to denote a capacityconstrained SFE that remains a capacity-constrained SFE after marginal changes in firms' forward sales. Moreover, firms' equilibrium supply functions are marginally changed after marginal changes in firms' forward sales.

As in the standard procedure of comparative statics, marginal changes in the stable capacity-constrained SFE can be analysed by a Taylor approximation around the equilibrium. In our case the non-linear differential equations in (2) can be linearized for infinitesimally small perturbation functions $\left\{t_{i}(p)\right\}_{i=1,2}$ of the supply functions $\left\{s_{i}(p)\right\}_{i=1,2}$.

Lemma 1. Let $i, j \in 1,2$ and $j \neq i$. Assume that firm $i$ increases its forward sales by an infinitesimally small amount $d x_{i}$, then the system of differential equation determining the perturbation functions of the net-supply equilibrium curves is given by:

$$
\left\{\begin{array}{c}
t_{i}^{\prime}(p)=\frac{\left[p-C_{j}{ }^{\prime}\left(q_{j}{ }^{0}(p)\right)\right] t_{j}(p)+s_{j}{ }^{0}(p) C_{j}{ }^{\prime \prime}\left(q_{j}{ }^{0}(p)\right) t_{j}(p)}{\left[p-C_{j}{ }^{\prime}\left(q_{j}{ }^{0}(p)\right)\right]^{2}} \\
t_{j}^{\prime}(p)=\frac{\left[p-C_{i}{ }^{\prime}\left(q_{i}{ }^{0}(p)\right)\right] t_{i}(p)+s_{i}{ }^{0}(p) C_{i}{ }^{\prime \prime}\left(q_{i}{ }^{0}(p)\right)\left[t_{i}(p)+d x_{i}\right]}{\left[p-C_{i}{ }^{\prime}\left(q_{i}{ }^{0}(p)\right)\right]^{2}}
\end{array}\right.
$$

Proof: See appendix.

We are now ready to prove the following:

Theorem 1. Consider a market situation for which a stable capacity-constrained SFE exists. If firm $i$ increases its forward sales by an infinitesimally small amount $d x_{i}$, then $-d x_{i} \leq t_{i}(p) \leq 0 \quad \forall p \in(\underline{p}, \bar{p})$.

Proof: See appendix. 
The proven inequality $-d x_{i} \leq t_{i}(p)$ implies that firm $i$ will shift its output curve $q_{i}(p)=s_{i}(p)+x_{i}$ (weakly) outwards when it increases its forward sales. Thus as expected, increased forward sales is a credible commitment to aggressive real-time market bidding. However, the output curve will shift outwards by an amount less than $d x_{i}$, because $t_{i}(p) \leq 0$. Thus the net-supply curve of firm $i, s_{i}(p)$, shifts (weakly) inwards. It follows from (4) that $s_{i}\left(p_{0}\right)$ remains fixed to zero, so there is no shift at the contracting point.

We realize from (2) that firm $j$ 's real-time market response depends on changes in the slope of its residual demand. Reduced net-sales at all real-time prices implies that on average $s_{i}^{\prime}(p)$ decreases when $x_{i}$ increases. Thus firm $j$ will on average face a less elastic residual demand and one would intuitively expect that firm $j$ would increase its mark-up for most price levels. Under some circumstances this is true for all price levels.

Theorem 2. Let $i, j \in 1,2$ and $j \neq i$. Consider a market situation for which a stable capacityconstrained SFE exists, such that $\frac{s_{i}(p) C_{i}{ }^{\prime \prime}\left(q_{i}^{0}(p)\right)}{p-C_{i}^{\prime}\left(q_{i}^{0}(p)\right)}$ is non-decreasing $\forall p \in\left(p_{0}, \bar{p}\right)$. Now, if firm $i$ increases its forward sales by an infinitesimally small amount $d x_{i}$, then $t_{j}(p) \leq 0$. Proof: See appendix.

We know from the first-order condition in (2) that $s_{j}^{\prime}(p)-D^{\prime}(p)=\frac{s_{i}(p)}{p-C_{i}^{\prime}\left(q_{i}^{0}(p)\right)}$ $\forall p \in\left(p_{0}, \bar{p}\right)$. Hence, assuming that $s_{j}^{\prime \prime}(p)-D^{\prime \prime}(p) \geq 0 \forall p \in\left(p_{0}, \bar{p}\right)$ implies that the ratio $\frac{s_{i}(p)}{p-C_{i}^{\prime}\left(q_{i}^{0}(p)\right)}$ is non-decreasing in the price in this interval. Moreover, if we also assume that $C_{i}{ }^{\prime \prime \prime}\left(q_{i}^{0}(p)\right) \geq 0 \forall p \in\left(p_{0}, \bar{p}\right)$, then we realize that the ratio $\frac{s_{i}(p) C_{i}{ }^{\prime \prime}\left(q_{i}^{0}(p)\right)}{p-C_{i}{ }^{\prime}\left(q_{i}^{0}(p)\right)}$ is nondecreasing in the price in this interval. Thus for a market in which firms have convex marginal costs and face a concave residual demand, then strategies are direct substitutes. 

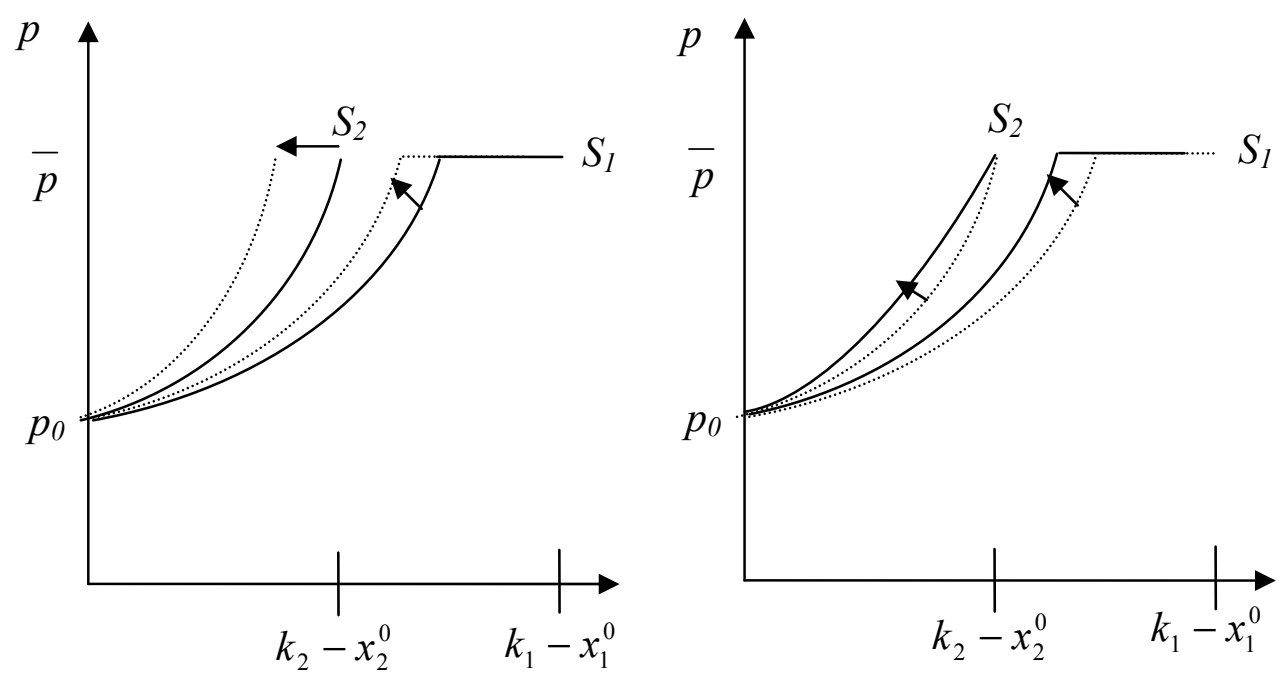

Figure 5. When firm i increases its forward sales, its net-supply, $s_{i}(p)$, shifts inwards. If firm $i$ has convex marginal costs and face a concave residual demand, then firm $j \neq i$ will also shift its net-supply inwards. In the left figure, firm 2 increases its forward sales. In the right figure, firm 1 increases its forward sales.

Green (1999) and Chung et al. (2004) show that strategies are direct neutrals for linear SFE. Marginal costs and residual demand are linear in that model, and $\frac{s_{i}(p) C_{i}^{\prime \prime}\left(q_{i}^{0}(p)\right)}{p-C_{i}^{\prime}\left(q_{i}^{0}(p)\right)}$ is a constant. Moreover, Klemperer and Meyer (1989) show that the linear SFE is the unique equilibrium if capacity constraints are infinite and demand shocks are be arbitrarily large, so the linear SFE is a capacity-constrained SFE when capacity is infinite. Thus the linear SFE is the limit case of capacity-constrained SFE with convex marginal costs and concave residual demand. In light of Theorem 2, it should not come as a surprise that strategies are direct neutrals for this limiting case. Given Theorem 2 and results for the linear SFE, a reasonable conjecture is that strategies would be direct complements if demand is linear and marginal costs are increasing and concave. This implies that capacity constraints need to be infinite to avoid local convexities in the marginal cost near the capacity constraint. A reasonable conjecture is that supply functions in the capacity-constrained SFE would be concave, $s_{j}{ }^{\prime \prime}(p) \leq 0$, under these circumstances and accordingly the residual demand of the producers would be convex. It is uncertain whether there are circumstances in real electricity markets, for which strategies are direct complements. However, based on the analysis in this section, it can be conjectured that the risk for such outcomes is largest for price levels near locally 
concave corners in the marginal cost steps, especially as supply functions are more likely to be locally concave at such price levels.

\subsection{The forward market}

Proceeding with the backward induction method we will now calculate the optimal contracting level given sequentially rational bidding strategies in the real-time market.

The total profit of firm $i$ (including forward sales) for a given shock realisation $\varepsilon$ is

$$
\pi_{i}(\varepsilon, \mathbf{x})=\underbrace{\left[s_{i}(p(\varepsilon, \mathbf{x}), \mathbf{x})+x_{i}\right.}_{q_{i}}] p(\varepsilon, \mathbf{x})+x_{i}\left[p^{f}-p(\varepsilon, \mathbf{x})\right]-C_{i} \underbrace{\left[s_{i}(p(\varepsilon, \mathbf{x}), \mathbf{x})+x_{i}\right.}_{q_{i}}] .
$$

The first term is the revenue in the real-time market. The second term is the arbitrage profit and the third term is the total cost. Strategic forward contracting is driven by shifts in competitors' output curve. To analyze these shifts firm $i$ 's output is expressed in demand and competitors' output. Thus (5) can be written:

$$
\begin{aligned}
& \pi_{i}=\overbrace{\left[D(p(\varepsilon, \mathbf{x}), \varepsilon)-q_{-i}(p(\varepsilon, \mathbf{x}), \mathbf{x})\right]}^{q_{i}} p(\varepsilon, \mathbf{x})+x_{i}\left[p^{f}-p(\varepsilon, \mathbf{x})\right] \\
& -C_{i} \underbrace{\left[D(p(\varepsilon, \mathbf{x}), \varepsilon)-q_{-i}(p(\varepsilon, \mathbf{x}), \mathbf{x})\right]}_{q_{i}} .
\end{aligned}
$$

Assume that $q_{-i}(p(\varepsilon, \mathbf{x}), \mathbf{x})$ is competitors' sequentially rational equilibrium response and let us now calculate the equilibrium contracting level of firm $i$. The marginal change in firm $i$ 's profit after a marginal change in $x_{i}$ is:

$$
\begin{aligned}
& \frac{d \pi_{i}}{d x_{i}}=\left(\frac{\partial D}{\partial p} \frac{d p}{d x_{i}}-\frac{\partial q_{-i}}{\partial p} \frac{d p}{d x_{i}}-\frac{\partial q_{-i}}{\partial x_{i}}-\sum_{j \neq i} \frac{\partial q_{-i}}{\partial x_{j}} \frac{d x_{j}}{d x_{i}}\right)\left[p-C_{i}^{\prime}\left(q_{i}\right)\right] \\
& +q_{i} \frac{d p}{d x_{i}}+p^{f}-p(\varepsilon, \mathbf{x})+x_{i}\left(\frac{d p^{f}}{d x_{i}}-\frac{d p}{d x_{i}}\right) .
\end{aligned}
$$

Note that the total derivative $\frac{d p}{d x_{i}}$ includes not only the direct effect $\frac{\partial p}{\partial x_{i}}$ but also indirect changes in the real-time price via changes in competitors' forward contracting levels. We see that the profit of firm $i$ for a given shock realisation $\varepsilon$ can change through four mechanisms. 1) Changes in output, both because of shifts in competitors' output curve and a changed realtime price. The additional profit is then given by the increased output times the markup, $p-C_{i}^{\prime}\left(q_{i}\right)$. 2) Changes in the real-time price will also change the mark-up for total sales, 
$\left.q_{i} .3\right)$ The arbitrage profit on any additional contract is given by $p^{f}-p(\varepsilon, \mathbf{x})$. 4) The arbitrage profit from the firm's contracts changes if $\frac{d p^{f}}{d x_{i}} \neq \frac{d p}{d x_{i}}$.

Using the assumption that real-time market bids are sequentially rational we will now simplify the expression in (7). But we first note that $s_{i}=q_{i}-x_{i}$ and that $\frac{\partial s_{-i}}{\partial p}=\frac{\partial q_{-i}}{\partial p}$. Thus (7) can be written on the following form:

$$
\begin{aligned}
& \frac{d \pi_{i}}{d x_{i}}=\frac{d p}{d x_{i}}\left\{\left(\frac{\partial D}{\partial p}-\frac{\partial s_{-i}}{\partial p}\right)\left[p-C_{i}^{\prime}\left(q_{i}\right)\right]+s_{i}\right\}+ \\
& -\left(\frac{\partial q_{-i}}{\partial x_{i}}+\sum_{j \neq i} \frac{\partial q_{-i}}{\partial x_{j}} \frac{d x_{j}}{d x_{i}}\right)\left\{p-C_{i}^{\prime}\left(q_{i}\right)\right\}+p^{f}-p(\varepsilon, \mathbf{x})+x_{i} \frac{d p^{f}}{d x_{i}} .
\end{aligned}
$$

Sequentially rational real-time market bids satisfy the KM condition in (1), also when firms deviate from their equilibrium forward contracting levels. Thus the first term is zero, and accordingly

$$
\frac{d \pi_{i}}{d x_{i}}=-\underbrace{\left(\frac{\partial q_{-i}}{\partial x_{i}}+\sum_{j \neq i} \frac{\partial q_{-i}}{\partial x_{j}} \frac{d x_{j}}{d x_{i}}\right)}_{W_{i}}\left[p-C_{i}^{\prime}\left(q_{i}\right)\right]+p^{f}-p(\varepsilon, \mathbf{x})+x_{i} \frac{d p^{f}}{d x_{i}} .
$$

Note that all $\frac{d p}{d x_{i}}$ derivatives have been cancelled out. Thus in a subgame perfect Nash equilibrium a marginal change in the real-time price has in itself no impact on the profit. This result and a corresponding result in the analysis of business strategies in sequential markets (Tirole, 2003) can be explained by the envelope theorem (Mas-Colell et al., 1995). With sequentially rational real-time market bids, the equilibrium real-time price maximizes a firm's profit for each shock outcome. Thus according to the first-order condition of a profit maximum, a marginal change in the real-time price has no influence on the profit. We realise from (8) that in equilibrium there are only three transmission mechanisms left through which firm $i$ 's profit is influenced by a marginal change in $x_{i} .1$ ) The shift of competitors' output curve, i.e. the extent to which supply functions are strategic substitutes. 2) The arbitrage profit on the additional contract. 3) Changes in the forward price.

In equilibrium, firm $i$ maximises its expected profit and its forward contracting level is given by the condition

$$
\frac{d E\left[\pi_{i}(\varepsilon, \mathbf{x})\right]}{d x_{i}}=\int_{\underline{\varepsilon}}^{\bar{\varepsilon}} \frac{d \pi_{i}(\varepsilon, \mathbf{x})}{d x_{i}} f(\varepsilon) d \varepsilon=0 .
$$


Let $\widehat{\mathbf{x}}$ denote the vector with firms' forward sales in equilibrium. It follows from (8) that firm $i$ 's forward position, $\hat{x}_{i}$, is implicitly determined by:

$$
\int_{\underline{\varepsilon}}^{\bar{\varepsilon}}\{-\underbrace{\left(\frac{\partial \hat{q}_{-i}}{\partial x_{i}}+\sum_{j \neq i} \frac{\partial \hat{q}_{-i}}{\partial x_{j}} \frac{d \bar{x}_{j}}{d x_{i}}\right)}_{W_{i}}\left[\hat{p}-C_{i}^{\prime}\left(q_{i}\right)\right]+p^{f}-p(\varepsilon, \widehat{\mathbf{x}})+\widehat{x}_{i} \frac{d p^{f}}{d x_{i}}\} f(\varepsilon) d \varepsilon=0 .
$$

In equilibrium, arbitrage profits are ruled out by risk-neutral speculators. Thus

$$
\int_{\underline{\varepsilon}}^{\bar{\varepsilon}}\{-\underbrace{\left(\frac{\partial \hat{q}_{-i}}{\partial x_{i}}+\sum_{j \neq i} \frac{\partial \hat{q}_{-i}}{\partial x_{j}} \frac{d \hat{x}_{j}}{d x_{i}}\right)}_{W_{i}}\left[\hat{p}-C_{i}^{\prime}\left(q_{i}\right)\right]+\hat{x}_{i} \frac{d p^{f}}{d x_{i}}\} f(\varepsilon) d \varepsilon=0 .
$$

Thus in the case of risk-neutral producers there are only two transmission mechanisms through which firm $i$ 's profit is influenced by a marginal change in $x_{i}$ : shifts of competitors' output curve, which it makes it possible to increase output at competitors' expense (the quantity effect), and changes in the forward price (the price effect).

\subsection{Evaluating the contracting condition}

It is instructive to rewrite the contracting condition in (11) on the following form:

$$
\mathrm{E}\left\{\left[\frac{W_{i}^{D}}{\frac{d p^{f}}{d x_{i}}}+\sum_{j \neq i} \frac{\partial q_{-i}(p, \mathbf{x})}{\partial x_{j}} \frac{\partial x_{j}}{\partial p^{f}}\right]\left[p(\varepsilon, \mathbf{x})-C_{i}^{\prime}\left(q_{i}(\varepsilon, \mathbf{x})\right)\right]\right\}=x_{i} .
$$

For given slopes of the forward supply curves, $\frac{d p^{f}}{d x_{i}}$ is reduced if the slope of forward demand becomes more elastic, i.e. the liquidity provided by speculators increases. Thus the direct strategic effect is amplified by liquidity provided by speculators, while the indirect strategic effect is unaffected. The indirect strategic effect increases if the elasticity in the forward supply increases, while the direct strategic effect is unaffected by this elasticity as long as $\frac{d p^{f}}{d x_{i}}$ is fixed.

The condition in (11) will now be evaluated for three specific cases: perfectly elastic forward supply, perfectly inelastic forward supply, and perfectly elastic demand. I start with perfectly elastic forward supply. In this case, strategies are indirect neutrals, because 
competitors' forward sales are not influenced by changes in the forward price, i.e. $\frac{d \bar{x}_{j}}{d x_{i}}=0 \forall j \neq i$. Green (1999) and Chung et al. (2004) refer to this case as the Cournot conjecture. In this case, a firm's level of forward contracting is determined by the extent to which strategies are direct substitutes and how sensitive the forward price is to increased forward sales.

$$
\mathrm{E}\left\{W_{i}^{D}[p(\varepsilon, \mathbf{x}), \mathbf{x}]\left[p(\varepsilon, \mathbf{x})-C_{i}^{\prime}\left(q_{i}(\varepsilon, \mathbf{x})\right)\right]\right\}=x_{i} \frac{d p^{f}}{d x_{i}}
$$

If supply function strategies are directly neutral as in Newbery (1998b), Green (1999), and Chung et al. (2004), then $W_{i}^{D}=0$ and producers' forward sales are zero. Moreover, the direct strategic effect is generally zero if forward sales are not observable and cannot be inferred, as in the two-stage Cournot model by Hughes and Kao (1997). In addition, a monopolist has $W_{i}^{D}=0$, because competitors' output is identically zero by definition, and this also results in zero contracting. However, in a oligopoly market in which forward sales are observable and strategies are direct substitutes, as in the Cournot models by Allaz and Vila (1993) and Bushnell (2007), then $W_{i}^{D}<0$ and it follows from (13) that $x_{i}>0$ (note that $\frac{d p^{f}}{d x_{i}}<0$ ). The same is also true for the duopoly market analyzed in Section 4.2 if firms have convex marginal costs and face concave residual demand. In a game in which strategies are direct complements we get $W_{i}^{D}>0$, as in Mahenc and Salanié (2004), and producers buy in the forward market, i.e. $x_{i}<0$.

If forward supply is perfectly elastic — a case which Green (1999) and Chung et al. (2004) refer to as the Bertrand conjecture - then $\frac{d p^{f}}{d x_{i}}=0$ and (11) can be simplified to:

$$
\mathrm{E}\left\{W_{i}[p(\varepsilon, \mathbf{x}), \mathbf{x}]\left[p(\varepsilon, \mathbf{x})-C_{i}^{\prime}\left(q_{i}(\varepsilon, \mathbf{x})\right)\right]\right\}=0 .
$$

If demand uncertainty is sufficiently small, then (14) implies that $p(\varepsilon, \mathbf{x}) \approx C_{i}^{\prime}\left(q_{i}(\varepsilon, \mathbf{x})\right)$. Zero mark-ups together with the first-order condition in (16) implies that $x_{i} \approx \mathrm{E}\left(q_{i}\right)$, i.e. forward sales equal expected output (full-contracting). Green (1999) and Chung et al. (2004) prove the same result for linear SFE, in which case demand uncertainty does not have to be small to get full-contracting. The intuition behind the full-contracting result is that the price effect is zero when the forward price is independent of forward sales. Then firms have incentives to 
increase their forward sales as long as the expected value of mark-ups times incremental output is positive.

Another interesting case to consider is when risk-neutral producers' face a perfectly elastic forward demand. As in Ferreira (2006) this is a plausible approximation for a market with many risk-neutral speculators. Because they should sell as many contracts they can if the forward price is above the expected real-time price and buy as many contracts they can if the forward price is below the expected real-time price. If we in addition assume that competitors' forward supply is not perfectly elastic, then there is no indirect effect, because the forward price cannot be changed. Accordingly, (11) can be written:

$$
\frac{d U_{i}}{d x_{i}}=\mathrm{E}\left\{-W_{i}^{D}\left[p-C_{i}^{\prime}\left(q_{i}\right)\right]\right\}
$$

With small demand uncertainty and direct strategic substitutes, $W_{i}^{D}<0$, the result is again full contracting. The contracting condition in (15) is also satisfied for full-contracting if strategies are complements, but this solution is a profit minimum. In this case, forward contracting will tend to either plus or minus infinity and both are catastrophic for welfare. Large forward sales implies huge mark-downs in the real-time market, which results in overproduction. Large negative sales results in huge mark-ups and under-production. Thus increasing speculative trading in an electricity market does not necessarily improve welfare, because it strengthens the direct strategic effect, which is not necessarily beneficial for welfare.

\section{CONCLUSIONS}

It is well-known that positive forward contracting is a credible commitment to aggressive spot market bidding and it significantly mitigates producers' market power in electricity markets. Still, it is often in producers' own interest to sell forward; risk-averse firms want to hedge their risk, for example. Moreover, in a market with imperfect competition, producers have strategic incentives to buy or sell contracts in the forward market. If strategies are substitutes, as in the Cournot model by Allaz and Vila (1993), then a commitment to aggressive spot market bidding results in a soft spot market response from competitors. This is similar to the first-mover advantage in a Stackelberg game. The difference to the Stackelberg game is that all firms can get the first-mover advantage by selling in the forward market. Thus all firms have incentives to sell forward to achieve a soft response in the spot market. But when they all do so no one succeeds in acquiring the leader advantage and all firms end up worse off. 
The result is that competition is tougher and welfare is improved compared to a situation without forward trading. On the other hand if strategies are complements, as in Mahenc and Salanié (2004), then producers commit to soft spot market bidding by buying in the forward market (negative contracting), which results in a soft spot market response from competitors. Newbery (1998b), Green (1999) and Chung et al. (2004) show that an indirect strategic effect is introduced if competitors' forward supply is elastic. In this case, a generator can reduce the forward price and competitors' forward sales (which shift competitors' output curve inwards) by increasing it own forward sales.

This paper theoretically analyses the strategic effects in the electricity market by means of a two-stage game in which producers compete with supply function strategies. Sequentially rational offer strategies in the real-time market are calculated by the supply function equilibrium (SFE) with uncertain demand. A unique SFE can be determined if maximum demand is sufficiently high to ensure that the capacity constraint of all firms but possibly the largest bind with a positive probability, which could be arbitrarily small. Applying this assumption to a duopoly market, it is shown that strategies are indirect substitutes and that a producer shifts its output curve outwards after increasing its forward sales. However, the netsupply curve of a firm shifts inwards in the spot market after it has increased its forward sales. Thus on average the competitor would face a less elastic residual demand in the spot market and one would therefore expect the competitor to increase its mark-up for most price levels. Hence, strategies would be direct substitutes in most cases. It is shown that strategies are always direct substitutes if firms have convex marginal costs and face concave residual demand. The result concurs with previous results for the limit case. It is known that when marginal costs and residual demand are both linear, as in the linear SFE model, then strategies are direct neutrals (Green, 1999; Chung et al., 2004).

Similar to the day-ahead market, consumers, producers and speculators are assumed to bid with offer and bid curves in the forward market. Risk-neutral speculators ensure that the forward price equals the expected spot price in equilibrium, but as in Ferreira (2006) this equality may not necessarily hold out of the equilibrium path. This is a difference compared to previous papers by e.g. Allaz and Vila (1993), Newbery (1998b), Green (1999) and Chung et al. (2004), where there are no arbitrage opportunities not even out of the equilibrium path; an assumption which is difficult to motivate game-theoretically and which is unnecessarily restrictive. This paper derives a contracting condition for multiple asymmetric producers with general cost functions, which is valid also for the general case with multiple equilibria in the real-time market. Sequentially rational spot market bids leads to an envelope result, a 
marginal change in the spot price because of changed forward sales has no influence on the expected profit. The optimal contracting level is determined by a quantity effect and a price effect. The quantity effect is that a producer can shift competitors' output inwards and increase its own output at their expense by increasing its forward sales. On the margin, increased output is attractive as long as the expected value of mark-up times incremental output is positive. Forward sales are curbed by a price effect, increased forward sales reduces the forward price, which is bad for profits. Thus optimal forward contracting very much depend on the sensitivity of the forward price to increased forward sales.

Increased elasticity of the forward demand implies that contracting incentives related to the direct strategic effect are strengthened, while contracting incentives related to the indirect strategic effect are unchanged. The indirect strategic effect is strengthened by increased elasticity in competitors' forward supply. The direct strategic effect, on the other hand, is unaffected of an increased elasticity in competitors' forward supply as long as the elasticity of residual demand in the forward market of the producer is fixed. If strategies are substitutes, then forward contracting is largest when residual demand in the forward market is perfectly elastic, so that the price effect is zero. In this case, producers will sell in the forward market as long as the expected value of mark-up times incremental output is positive. With small demand uncertainty, the mark-up in the spot market will be zero in equilibrium, which is very beneficial for welfare. This is a generalisation of the results for linear SFE by Green (1999) and Chung et al. (2004).

Strategies are indirect substitutes for all well-behaved markets. Thus increased elasticity of forward supply should always be beneficial to welfare as it would strengthen the indirect strategic effect. Elastic forward demand, provided by risk-neutral speculators for example, strengthens the direct strategic effect. This is beneficial for welfare if strategies are direct substitutes, which is likely but not certain for electricity markets.

The results in this paper are based on the assumption that the resulting equilibrium prices are low enough to discourage entry. An interesting topic for future research is to consider the threat of entry as in Newbery (1998b). The results in the literature on strategic forward contracting very much depend on the elasticity of offers and bids in the forward market. A more detailed model of this market, which could endogeneously determine these slopes would be very useful. 


\section{REFERENCES}

B. Allaz and J-L Vila (1993), "Cournot competition, forward markets and efficiency", Journal of Economic Theory, Vol. 59, pp. 1-16.

E. J. Anderson and H. Xu (2005), "Supply Function Equilibrium in Electricity Spot Markets with Contracts and Price Caps“, Journal of Optimization Theory and Applications, Vol. 124, No. 2, pp. 257-283.

E. J. Anderson and X. Hu (2006), Finding Supply Function Equilibria with Asymmetric Firms, Workshop on Supply Function Equilibrium Modelling of Electricity Markets, April 2006, Auckland, New Zealand.

F. Bolle (1992), "Supply function equilibria and the danger of tacit collusion. The case of spot markets for electricity”, Energy Economics, Vol. 14, pp. 94-102.

J. Brandts, P. Pezanis-Christou and A. Schram (2006), "Competition with Forward Contracts: A Laboratory Analysis Motivated by Electricity Market Design". Forthcoming in Economic Journal.

J. Bushnell (2007), “Oligopoly Equilibria in Electricity Contract Markets”, Journal of Regulatory Economics, Vol. 32, pp. 225-245.

T.S. Chung, S.H. Zhang, K.P. Wong, C.W. Yu and C.Y. Chung (2004), "Strategic forward contracting in electricity markets: modelling and analysis by equilibrium method", IEE Proceedings on. Generation. Transmission and. Distribution, Vol. 151, No. 2, pp. 141-149.

J. L. Ferreira (2006), The Role of Observability in Futures Markets, Topics in Theoretical Economics, Vol. 6, No. 1, Article 7.

N.-H. von der Fehr and D. Harbord (1992), Long-Term Contracts and Imperfectly Competitive Spot Markets: A Study of the UK Electricity Industry, University of Oslo Economics Memorandum No. 14/1992. 
T. Genc and S. Reynolds (2004). Supply Function Equilibria with Pivotal Electricity Suppliers, Eller College Working Paper No.1001-04, University of Arizona.

R.J. Green (1999), “The Electricity Contract Market in England and Wales”, Journal of Industrial Economics, Vol. XLVII, No. 1, pp.107-124.

R.J. Green and D.M. Newbery (1992), "Competition in the British Electricity Spot Market”, Journal of Political Economy, Vol. 100, No. 5, pp. 929-953.

Holmberg, P. (2005b). Numerical calculation of asymmetric supply function equilibrium with capacity constraints, Working Paper 2005:12, Department of Economics, Uppsala University.

P. Holmberg (2007), "Supply Function Equilibrium with Asymmetric Capacities and Constant Marginal Costs", Energy Journal, Vol. 28, No. 2, pp. 55-82.

J. S. Hughes and J.L. Kao (1997), "Strategic forward contracting and observability", International Journal of Industrial Organization, Vol. 16, No. 1, pp. 121-133.

J. C. Hull (1997), Options, futures and other derivatives, Prentice-Hall International (UK): London.

P.D. Klemperer and M.A. Meyer (1989), "Supply function equilibria in an oligopoly under uncertainty", Econometrica, Vol. 57, pp. 1243-1277.

P. Mahenc and F. Salanie (2004), "Softening competition through forward trading”, Journal of Economic Theory, Vol. 116, pp. 282-293.

A. Mas-Colell, M. Whinston, and J. Green (1995). Microeconomic Theory. Oxford University Press: Oxford.

D. M. Newbery (1998a), "Pool Reform and Competition in Electricity", Ch..5, pp.117-166 in M. Beesley (ed.) Regulating Utilities: Understanding the Issues, London: Institute of Economic Affairs. 
D. M. Newbery (1998b), "Competition, contracts, and entry in the electricity spot market”, RAND Journal of Economics, Vol. 29, No. 4, pp. 726-749.

S. Stoft (2002), Power System Economics, New York: John Wiley \& Sons.

J. Tirole (2003). The Theory of Industrial Organization, Cambridge, MA: MIT Press.

F.A. Wolak (2000). “An Empirical Analysis of the Impact of Hedge Contracts on Bidding Behavior in a Competitive Electricity Market," International Economic Journal, Vol. 14, No. 2, pp. 1-39.

\section{Appendix}

\section{Proof of Lemma 1:}

It is straightforward to rewrite the first-order equation of firm $j$ on the standard form (Baldick and Hogan, 2002):

$$
s_{j}^{\prime}(p)=D^{\prime}(p)+\frac{s_{i}(p)}{p-C_{i}^{\prime}\left(q_{i}(p)\right)} \text {. }
$$

The change in the supply function of firm $j$ is defined by $t_{j}(p) \equiv s_{j}{ }^{1}(p)-s_{j}{ }^{0}(p)$. The differential equation driving this function is accordingly given by:

$$
\begin{aligned}
& t_{j}^{\prime}(p)=s_{j}{ }^{\prime 1}(p)-s_{j}^{\prime 0}(p)=D^{\prime}(p)+\frac{s_{i}{ }^{1}(p)}{p-C_{i}{ }^{\prime}\left(q_{i}{ }^{1}(p)\right)}-D^{\prime}(p)-\frac{s_{i}{ }^{0}(p)}{p-C_{i}{ }^{\prime}\left(q_{i}{ }^{0}(p)\right)}= \\
& =\frac{s_{i}{ }^{1}(p)}{p-C_{i}{ }^{\prime}\left(q_{i}{ }^{1}(p)\right)}-\frac{s_{i}{ }^{0}(p)}{p-C_{i}{ }^{\prime}\left(q_{i}{ }^{0}(p)\right)} .
\end{aligned}
$$

The first-order Taylor approximation can be used to simplify this expression, because the difference $t_{j}(p) \equiv s_{j}{ }^{1}(p)-s_{j}{ }^{0}(p)$ is infinitesimally small for a stable capacity-constrained SFE if $d x_{i}$ is infinitesimally small. Hence,

$$
t_{j}^{\prime}(p)=\frac{\left[p-C_{i}^{\prime}\left(q_{i}^{0}(p)\right)\right] t_{i}(p)+s_{i}{ }^{0}(p) C_{i}{ }^{\prime \prime}\left(q_{i}{ }^{0}(p)\right)\left[t_{i}(p)+d x_{i}\right]}{\left[p-C_{i}{ }^{\prime}\left(q_{i}^{0}(p)\right)\right]^{2}}
$$

An analogous expression can be derived for $t_{i}{ }^{\prime}(p)$. This can be simplified, because by assumption we have that $d x_{i}=0$. 


$$
t_{i}^{\prime}(p)=\frac{\left[p-C_{j}^{\prime}\left(q_{i}^{0}(p)\right)\right] t_{j}(p)+s_{j}^{0}(p) C_{j}{ }^{\prime \prime}\left(q_{j}{ }^{0}(p)\right) t_{j}(p)}{\left[p-C_{j}^{\prime}\left(q_{j}^{0}(p)\right)\right]^{2}} .
$$

\section{Proof of Theorem 1:}

The differential equation driving $t(p)$, which has been defined in Lemma 1, can be used to rule out values of $t_{i}$ outside the range $-d x_{i} \leq t_{i}(p) \leq 0$. Because, as shown in the Table below, states outside this range will imply that at least one of the boundary conditions will be violated. To simplify the interpretation, the boundary conditions in (3) and (4) are expressed in $t(p)$.

$$
t_{2}(\bar{p})=-d x_{2} \text { and } t_{1}\left(p_{0}\right)=t_{2}\left(\left(p_{0}\right)\right)=0 .
$$

\begin{tabular}{|c|c|c|c|c|}
\hline State at price $p$ & $\begin{array}{l}\text { Implication for } \\
\text { derivatives at } p \\
\text { from Lemma } 1\end{array}$ & $\begin{array}{l}\text { Critical } \\
\text { interval }\end{array}$ & Implication from Lemma 1 & $\begin{array}{l}\text { Violated } \\
\text { boundary } \\
\text { condition }\end{array}$ \\
\hline$t_{i}<-d x_{i} \quad t_{j} \leq 0$ & $t_{i}^{\prime} \leq 0 \quad t_{j}^{\prime}<0$ & $(p, \bar{p})$ & $\begin{array}{l}\text { Both } t_{i} \text { and } t_{j} \text { are negative } \\
\text { and decreasing in interval }\end{array}$ & $t_{2}(\bar{p})=-d x_{2}$ \\
\hline$t_{i}<-d x_{i} \quad t_{j} \geq 0$ & $t_{i}^{\prime} \geq 0 \quad t_{j}^{\prime}<0$ & $\left(p_{0}, p\right)$ & $\begin{array}{l}t_{i} \text { is increasing and } \\
\text { negative in interval. } \\
t_{j} \text { is decreasing and } \\
\text { positive in interval }\end{array}$ & $t_{1}\left(p_{0}\right)=t_{2}\left(p_{0}\right)=0$ \\
\hline$t_{i}>0 \quad t_{j} \geq 0$ & $t_{i}^{\prime} \geq 0 \quad t_{j}^{\prime}>0$ & $(p, \bar{p})$ & $\begin{array}{l}\text { Both } t_{i} \text { and } t_{j} \text { are positive } \\
\text { and increasing in interval }\end{array}$ & $t_{2}(\bar{p})=-d x_{2}$ \\
\hline$t_{i}>0 \quad t_{j} \leq 0$ & $t_{i}^{\prime} \leq 0 \quad t_{j}^{\prime}>0$ & $\left(p_{0}, p\right)$ & $\begin{array}{l}t_{i} \text { is decreasing and } \\
\text { positive in interval. } \\
t_{j} \text { is increasing and } \\
\text { negative in interval }\end{array}$ & $t_{1}\left(p_{0}\right)=t_{2}\left(p_{0}\right)=0$ \\
\hline
\end{tabular}




\section{Proof of Theorem 2:}

We know from Theorem 1 that $-d x_{i} \leq t_{i} \leq 0$. Using the monotonicity property of $\frac{s_{i}(p) C_{i}^{\prime \prime}\left(q_{i}^{0}(p)\right)}{p-C_{i}^{\prime}\left(q_{i}^{0}(p)\right)}$, we can now rule out $t_{j}(\mathrm{p})>0$ by means of a similar procedure as in the proof of Theorem 1.

\begin{tabular}{|c|c|c|c|c|}
\hline State at price $p$ & $\begin{array}{l}\text { Implication for } \\
\text { derivatives at } p \\
\text { from Lemma } 1\end{array}$ & $\begin{array}{l}\text { Critical } \\
\text { interval }\end{array}$ & $\begin{array}{l}\text { Implication from Lemma } 1 \\
\text { And monotonicity of } \\
\frac{s_{i}(p) C_{i}^{\prime \prime}\left(q_{i}^{0}(p)\right)}{p-C_{i}^{\prime}\left(q_{i}^{0}(p)\right)}\end{array}$ & $\begin{array}{l}\text { Violated } \\
\text { boundary } \\
\text { condition }\end{array}$ \\
\hline $\begin{aligned}-d x_{i} \leq t_{i} \leq 0 & t_{j}>0 \\
& t_{j} \leq 0\end{aligned}$ & $t_{i}^{\prime}>0$ & $\left(p_{0}, p\right)$ & $\begin{array}{l}t_{i} \text { is increasing and } \\
\text { negative in interval. } \\
t_{j} \text { is decreasing and } \\
\text { positive in interval }\end{array}$ & $t_{1}\left(p_{0}\right)=t_{2}\left(p_{0}\right)=0$ \\
\hline $\begin{array}{ll}-d x_{i} \leq t_{i} \leq 0 & t_{j}>0 \\
& t_{j}^{\prime} \geq 0\end{array}$ & $t_{i}^{\prime}>0$ & $(p, \bar{p})$ & $\begin{array}{l}t_{j} \text { is positive and increasing } \\
\text { in interval. } t_{i} \text { is increasing } \\
\text { in interval. }\end{array}$ & $t_{2}(\bar{p})=-d x_{2}$ \\
\hline
\end{tabular}

